\title{
Systemic Process Improvement Study of Avocado Oil Extraction with Hexane
}

\author{
Shaun Mgoma ${ }^{1}$, Moses Basitere ${ }^{1}$, and Vusi Mshayisa ${ }^{1}$ \\ ${ }^{1}$ Cape Peninsula University of Technology - Bellville Campus
}

July 27,2020

\begin{abstract}
The increase in healthy lifestyle has resulted in an increased demand of both the avocado fruit and its oil production. The growth in demand has prompted a need for an industry expansion and an efficient process that produces high quality oil. This study therefore explored solid-liquid oil extraction using hexane at different process parameters to determine the optimum conditions which produce a higher yield of avocado oil. Furthermore, the study analysed oil produced from different parameters and evaluated its stability and fatty acid content. The oil stability was evaluated by analyzing oxidative stability and peroxide value. Observations at higher temperatures showed oil production of high stability containing lower content of trans fats, which are undesired and detrimental for human consumption. The efficient extraction conditions found with the aid of response surface methodology (RSM) optimization were found to be a solvent ratio of $1.53 \mathrm{ml} / \mathrm{g}$ at a temperature of $60 \mathrm{C}$ for 128 minutes. The overall aim of the study was to improve the efficiency of the extraction process by increasing the yield of oil without compromising quality. The oil production process was found to be efficient such that the industry can be expanded to have avocado cultivars dedicated to oil production using hexane.
\end{abstract}

\section{Hosted file}

Systemic Process Improvement Study of Avocado Oil Extraction with Hexane_Wiley_Final.docx available at https://authorea.com/users/346641/articles/472574-systemic-process-improvementstudy-of-avocado-oil-extraction-with-hexane 